\title{
Phylogenetic relationships among the Chromatiaceae, their taxonomic reclassification and description of the new genera Allochromatium, Halochromatium, Isochromatium, Marichromatium, Thiococcus, Thiohalocapsa and Thermochromatium
}

\author{
Johannes F. Imhoff, Jörg Süling and Ralf Petri
}

Institut für Meereskunde an der Universität Kiel, Abteilung Marine Mikrobiologie, Düsternbrooker Weg 20 D-24105 Kiel, Germany
Author for correspondence: Johannes F. Imhoff. Tel: +49431 6973850 . Fax: +49431565876. e-mail: jimhoff $@$ ifm.uni-kiel.de

Sequences of the $16 \mathrm{~S}$ rDNA from all available type strains of Chromatium species have been determined and were compared to those of other Chromatiaceae, a few selected Ectothiorhodospiraceae and Escherichia coli. The clear separation of Ectothiorhodospiraceae and Chromatiaceae is confirmed. Most significantly the sequence comparison revealed a genetic divergence between Chromatium species originated from freshwater sources and those of truly marine and halophilic nature. Major phylogenetic branches of the Chromatiaceae contain (i) marine and halophilic species, (ii) freshwater Chromatium species together with Thiocystis species and (iii) species of the genera Thiocapsa and Amoebobacter as recently reclassified [Guyoneaud, R. \& 6 other authors (1998). Int J Syst Bacteriol 48, 957-964], namely Thiocapsa roseopersicina, Thiocapsa pendens (formerly Amoebobacter pendens), Thiocapsa rosea (formerly Amoebobacter roseus), Amoebobacter purpureus and Thiolamprovum pedioforme (formerly Amoebobacter pedioformis). The genetic relationships between the species and groups are not in congruence with the current classification of the Chromatiaceae and a reclassification is proposed on the basis of $16 \mathrm{~S}$ rDNA sequence similarity supported by selected phenotypic properties. The proposed changes include the transfers of Chromatium minus and Chromatium violascens to Thiocystis minor comb. nov. and Thiocystis violascens comb. nov., of Chromatium vinosum, Chromatium minutissimum and Chromatium warmingii to the new genus Allochromatium as Allochromatium vinosum comb. nov., Allochromatium minutissimum comb. nov., and Allochromatium warmingii comb. nov., of Chromatium tepidum to the new genus Thermochromatium as Thermochromatium tepidum comb. nov., of Chromatium salexigens and Chromatium glycolicum to the new genus Halochromatium as Halochromatium salexigens comb. nov. and Halochromatium glycolicum comb. nov., of Chromatium gracile and Chromatium purpuratum to the new genus as Marichromatium gracile comb. nov. and Marichromatium purpuratum comb. nov., of Thiocapsa pfennigii to Thiococcus pfennigii gen. nom. rev., of Thiocapsa halophila to the new genus Thiohalocapsa as Thiohalocapsa halophila comb. nov., and of Chromatium buderi to the new genus Isochromatium as Isochromatium buderi comb. nov.

Keywords: phylogeny, Chromatiaceae, taxonomic reclassification 


\section{INTRODUCTION}

Historically, the taxonomy of phototrophic purple sulfur bacteria, has been based on easily recognizable phenotypic properties (see Pfennig \& Trüper, 1974). The traditional taxonomic system of these bacteria is not phylogenetically oriented. It is primarily of practical relevance, and inconsistencies between the taxonomic treatment and genetic relationships of the purple sulfur bacteria have been discussed previously (Gibson et al., 1979; Fowler et al., 1984; Stackebrandt et al., 1984; Trüper, 1987). Indeed, phylogenetic information became available only with the establishment of sequencing techniques for proteins and nucleic acids on the basis of sequences of cytochrome $c$ (Ambler et al., 1979; Dickerson, 1980) and oligonucleotides obtained from 16S rRNA digestion with specific endonucleases (Gibson et al., 1979; Fowler et al., 1984; Stackebrandt et al., 1984), later by sequences of the 16S rRNA gene. It was obvious already from the early investigations on the genetic relationships that phototrophic bacteria are found in several major branches of a sequence-based phylogenetic bacterial system (see Woese, 1987), in part separated from and in part intermixed with non-phototrophic bacteria. Among the phototrophic purple bacteria, separate phylogenetic lines are represented by the purple sulfur bacteria (Chromatiaceae and Ectothiorhodospiraceae) in the $\gamma$-Proteobacteria and by the purple non-sulfur bacteria in the $\alpha$-Proteobacteria and the $\beta$-Proteobacteria. First surveys on the relationships of purple sulfur bacteria have been made by comparison of oligonucleotide catalogues (Fowler et al., 1984; Stackebrandt et al., 1984). More recently, sequence analyses and comparisons lead to the separation of the Ectothiorhodospiraceae into two genera that can also be recognized by their salt responses and other phenotypic properties (Imhoff \& Süling, 1996). 16S rDNA sequences of only a few species of the Chromatiaceae were available until recently (DeWeerd et al., 1990; Wahlund et al., 1991; Caumette et al., 1997; Guyoneaud et al., 1997, 1998). In the present work 16S rDNA sequences of all available type strains of Chromatium species are compared to related purple sulfur bacteria and used to characterize their genetic relationships. On this basis and with the additional support of phenotypic properties a reclassification of these bacteria is proposed. A positive correlation between differences in several phenotypic properties to similarities of $16 \mathrm{~S}$ rDNA sequences is discussed and in particular these properties are considered to be of importance for the classification of these bacteria.

\section{METHODS}

Source and culture of bacterial strains. All strains of purple sulfur bacteria used for this study are listed in Table 1, which in addition shows the previously used and the newly proposed names, the original strain designations, the DSM numbers when available and the EMBL accession numbers for their $16 \mathrm{~S}$ rDNA sequences. Cultures of all strains are maintained in our laboratory (see Table 1).
Strains were cultivated in synthetic medium according to Pfennig \& Trüper (1992). The final $\mathrm{pH}$ was $7 \cdot 2$. For marine and halophilic strains, $1-10 \% \mathrm{NaCl}$ was added to the medium, as required. Pure cultures were grown in $100 \mathrm{ml}$ screw-capped bottles completely filled with synthetic medium and incubated in the light.

PCR amplification and 16S rDNA sequencing and analysis. Cell material for 16S rDNA sequencing was taken from 1-2 ml of well-grown liquid cultures. DNA was extracted and purified by using the QIAGEN genomic DNA buffer set. Recombinant Taq polymerase was used for PCR (Mullis \& Faloona, 1987) which was started with the following primers: 5'-GTTTGATCCTGGCTCAG-3' and 5'-TACCTTGTTACGACTTCA-3' (positions 11-27 and 1489-1506, respectively, according to the Escherichia coli $16 \mathrm{~S}$ rRNA numbering of the International Union of Biochemistry). The PCR products were purified by using the QIAquick PCR purification kit. Sequences were obtained by cycle sequencing with the SequiTherm sequencing kit (Biozym) and the chain-termination reaction (Sanger et al., 1977) using an automated laser fluorescence sequencer (Pharmacia). Sequences were aligned using the CLUSTAL W program (Thompson et al., 1994). The alignment length was from positions 29 to 1381 according to the Escherichia coli numbering (including gaps 1400 positions). The distance matrix was calculated on the basis of the algorithm of Jukes \& Cantor (1969) with the DNADIST program within the PHYLIP package (Felsenstein, 1989). The FITCH program in the PHYLIP package fitted a tree to the evolutionary distances.

Nucleotide sequence accession numbers. The $16 \mathrm{~S}$ rDNA sequences determined in this study have been deposited in the EMBL database under accession numbers given in Table 1. Accession numbers of additional 16S rDNA sequences of Chromatiaceae that were published previously are also contained in Table 1. Further sequences (accession nos in parentheses) from Ectothiorhodospiraceae and Escherichia coli (K02555) were available from the EMBL database: Ectothiorhodospira mobilis strain DSM 237 ${ }^{\mathrm{T}}$ (X93481), Ectothiorhodospira haloalkaliphila strain ATCC 51935" (X93479), Ectothiorhodospira shaposhnikovii strain DSM 239 (X93480), Halorhodospira halophila strain DSM 244 (M26630), and Halorhodospira halochloris DSM 1059 (M59152) (see Imhoff \& Süling, 1996).

\section{RESULTS}

The relationships of the investigated type strains of Chromatium species and related purple sulfur bacteria based on almost complete sequences of the 16S rDNA is shown in a distance matrix with similarity values and $K_{\text {nuc }}$ values (Table 2) and a phylogenetic tree, based on the data from this distance matrix (Fig. 1).

It is quite apparent from their genetic relationships that a major deeply branching cluster with marine and halophilic Chromatiaceae species is clearly separated from another branch with predominantly freshwater species. Within this latter branch, one cluster contains Thiocapsa and Amoebobacter species according to Guyoneaud et al. (1998), while another one includes freshwater Chromatium species together with known Thiocystis species.

The first branch consists of Chromatium species which have been isolated from marine and hypersaline environments and which specifically and character- 
Table 1. Species and strains of Chromatiaceae compared in this study

Type strains are denoted by ${ }^{\mathrm{T}}$; $\mathrm{NN}$, not available in this collection.

\begin{tabular}{|c|c|c|c|c|c|}
\hline Previous name & New name & $\begin{array}{c}\text { DSM } \\
\text { no. }\end{array}$ & $\begin{array}{c}\text { Other } \\
\text { designation(s) }\end{array}$ & $\begin{array}{c}\text { Authors' } \\
\text { no. }\end{array}$ & EMBL no. \\
\hline Chromatium okenii & Unchanged & $169^{\mathrm{T}}$ & 1111 & 6010 & Y 12376 \\
\hline Chromatium vinosum & Allochromatium vinosum & $180^{\mathrm{T}}$ & $\mathrm{D}$ & 5110 & M26629 \\
\hline Chromatium minutissimum & Allochromatium minutissimum & $1376^{\mathrm{T}}$ & MSU & 5310 & Y 12369 \\
\hline Chromatium warmingii & Allochromatium warmingii & $173^{\mathrm{T}}$ & 6512 & 5810 & Y12365 \\
\hline Chromatium tepidum & Thermochromatium tepidum & $3771^{\mathrm{T}}$ & $\mathrm{MC}$ & $\mathrm{NN}$ & M59150 \\
\hline Chromatium minus & Thiocystis minor & $178^{\mathrm{T}}$ & 1211 & 5710 & Y 12372 \\
\hline Chromatium violascens & Thiocystis violascens & $168^{\mathrm{T}}$ & 6111 & 5410 & $\mathrm{AJ} 224438$ \\
\hline Chromatium purpuratum & Marichromatium purpuratum & $1591^{\mathrm{T}}$ & 984 & 5500 & $\mathrm{AJ} 224439$ \\
\hline Chromatium gracile & Marichromatium gracile & $203^{\mathrm{T}}$ & 8611 & 5210 & X93473 \\
\hline Chromatium buderi & Isochromatium buderi & $176^{\mathrm{T}}$ & 8111 & 5610 & $\mathrm{AJ} 224430$ \\
\hline Chromatium salexigens & Halochromatium salexigens & $4395^{\mathrm{T}}$ & SG3201 & 6310 & X98597 \\
\hline Chromatium glycolicum & Halochromatium glycolicum & $11080^{\mathrm{T}}$ & SL3201 & 6410 & X93472 \\
\hline Thiocapsa pfennigii & Thiococcus pfennigii & 226 & 8013 & 4250 & Y12373 \\
\hline Thiocapsa halophila & Thiohalocapsa halophila & $6210^{\mathrm{T}}$ & SG3202 & 4270 & AJ002796 \\
\hline Thiorhodovibrio winogradskyi & Unchanged & $6702^{\mathrm{T}}$ & 06511 & 4910 & Y 12368 \\
\hline Thiocystis violacea & Unchanged & $207^{\mathrm{T}}$ & 2711 & 4340 & Y11315 \\
\hline Thiocystis gelatinosa & Unchanged & $215^{\mathrm{T}}$ & 2611 & 4310 & Y11317 \\
\hline Rhabdochromatium marinum & Unchanged & $5261^{\mathrm{T}}$ & 8315 & 6510 & $\mathrm{X} 84316$ \\
\hline Thiorhodococcus minus & Thiorhodococcus minor* & $11518^{\mathrm{T}}$ & CE2203 & 6680 & Y11316 \\
\hline Amoebobacter purpureus & Unchanged & $4197^{\mathrm{T}}$ & ThSchl2 & 4450 & Y 12366 \\
\hline Thiocapsa roseopersicina & Unchanged & $217^{T}$ & 1711 & 4210 & Y 12364 \\
\hline Amoebobacter pendens & Thiocapsa pendens $\dagger$ & $236^{\mathrm{T}}$ & 1314 & 4410 & AJ002797 \\
\hline
\end{tabular}

* Corrected epithet.

† See Guyoneaud et al. (1998).

istically require various concentrations of salt for growth. Chromatium salexigens and Chromatium glycolicum form one line. Chromatium gracile and Chromatium purpuratum form a second line together with an isolate that has been first described as 'Rhodobacter marinus' (Burgess et al., 1994; 16S rDNA sequence of this strain as personal communication of T. Matsunaga). Also, Thiocapsa pfennigii and Thiocapsa halophila belong to this cluster and therefore certainly can no longer be classified as Thiocapsa species (Guyoneaud et al., 1998). In addition, Thiorhodovibrio winogradskyi, Rhabdochromatium marinum. Thiorhodococcus minor and Chromatium buderi form well-separated lines within this cluster (Fig. 1).

The second branch mostly contains species that originate from freshwater habitats and is significantly distinct from the branch of truly marine and halophilic species. On the basis of the sequence data, two major clusters can be recognized, one with Chromatium and Thiocystis species, the other with Thiocapsa and Amoebobacter species, including Thiolamprovum pedioforme (formerly Amoebobacter pedioformis).

In the first cluster Chromatium warmingii, Chromatium vinosum and Chromatium minutissimum form one subcluster to which Chromatium tepidum is distantly related. A second subcluster is represented by Chromatium minus, Thiocystis violacea, Thiocystis gelatinosa and Chromatium violascens. Chromatium okenii, the type species of the genus Chromatium, is only distantly related to other bacteria of this cluster. Chromatium weissei, which is phenotypically quite similar to Chromatium okenii, also has a number of significant positions in its $16 \mathrm{~S}$ rDNA sequence in common specifically with Chromatium okenii, as could be delineated from the comparison of its oligonucleotide catalogue (Fowler et al., 1984) with the sequence of Chromatium okenii. A pure culture of Chromatium weissei is at present not available and therefore the comparison of its complete sequence was not possible.

The second cluster of this branch showed some distant relationships to the freshwater Chromatium species. In this cluster are Thiolamprovum pedioforme (formerly Amoebobacter pedioformis), Amoebobacter purpureus, Thiocapsa pendens (formerly Amoebobacter pendens), Thiocapsa rosea (formerly Amoebobacter roseus) and Thiocapsa roseopersicina (Fig. 1; Guyoneaud et al., 1998). Although most of these species characteristically are found in freshwater habitats, a number of 
Table 2. Levels of $16 \mathrm{~S}$ rDNA sequence similarity and evolutionary distances of presently recognized Chromatium species with other phototrophic purple sulfur bacteria and Escherichia coli as reference species

The values on the upper right are the uncorrected sequence similarities (\%), and the values on the lower left are $K_{\text {nuc }}$ values corrected for multiple base change by the methods of Jukes \& Cantor (1969). Organisms: 1, Marichromatium purpuratum DSM $1591^{\top} ; 2$, Marichromatium gracile DSM $203^{\top} ; 3$, Halochromatium glycolicum DSM $11080^{\top} ; 4$, Halochromatium salexigens DSM 4395 $5^{\top}$; 5 , Isochromatium buderi DSM $176^{\top}$; 6 , Thiococcus pfennigii DSM 226; 7 , Thiohalocapsa halophila DSM $6210^{\top} ; 8$, Thiocapsa roseopersicina DSM $217^{\top}$;

9, Thiocapsa rosea DSM $235^{\mathrm{T}} ; 10$, Thiolamprovum pedioforme DSM $3802^{\mathrm{T}} ; 11$, Thiocystis violascens DSM $168^{\mathrm{T}} ; 12$, Thiocystis gelatinosa DSM $215^{\mathrm{T}}$; 13 , Thiocystis minor DSM $178^{\mathrm{T}}$;

14. Thiocystis violacea DSM $207^{\top} ; 15$, Chromatium okenii DSM $169^{\top} ; 16$, Allochromatium vinosum DSM $180^{\top} ; 17$, Allochromatium minutissimum DSM $1376^{\mathrm{T}}$; 18 , Allochromatium warmingii DSM $173^{\mathrm{T}} ; 19$, Thermochromatium tepidum DSM $3771^{\mathrm{T}} ; 20$, Thiocapsa pendens DSM $236^{\top}$; 21 , Amoebobacter purpureus DSM $4197^{\top} ; 22$, Thiorhodovibrio winogradskyi DSM $6702^{\mathrm{T}} ; 23$, Rhabdochromatium marinum DSM $5261^{\mathrm{T}} ; 24$, Thiorhodococcus minor DSM $11518^{\mathrm{T}} ; 25$, Escherichia coli; 26 , Ectothiorhodospira shaposhnikovii DSM $243^{\mathrm{\top}}$;

27, Ectothiorhodospira vacuolata DSM $2111^{\mathrm{T}} ; 28$, Ectothiorhodospira marismortui DSM $4180^{\mathrm{T}} ; 29$, Ectothiorhodospira haloalkaliphila ATCC 51935 ${ }^{\mathrm{T}}$; 30 , Ectothiorhodospira mobilis

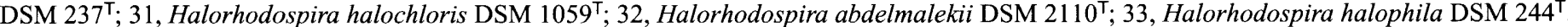

\begin{tabular}{|c|c|c|c|c|c|c|c|c|c|c|c|c|c|c|c|c|c|c|c|c|c|c|c|c|c|c|c|c|c|c|c|c|c|}
\hline & 1 & 2 & $3^{3}$ & 4 & 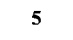 & 8 & 7 & 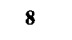 & & 10 & & & & & & & & & & & & & & & & & & & & & & & 3 \\
\hline 1 & & & 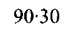 & 27 & & 50 & $92 \cdot 24$ & 34 & 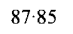 & 43 & 89.53 & 83 & $89 \cdot 88$ & $m$ & 46 & 10 & & 9.05 & & 1.31 & & 4 & 05 & $92 \cdot 37$ & 70 & 39 & 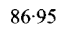 & 30 & 1 & .21 & .90 & & \\
\hline 2 & .066 & & $91 \cdot 41$ & 89 & 69 & 43 & 23 & 03 & 39 & 40 & 91 & & . 31 & 69 & & 13 & & & & & & & 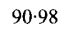 & 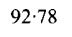 & & & 88.02 & 81.34 & & & & & 6. \\
\hline 3 & $0 \cdot 104$ & 091 & & $95 \cdot 19$ & & & & & & & 62 & & & 66 & & & & 7.69 & & & & & & 92.54 & 24 & 88.59 & 87.4 & $87 \cdot 80$ & 88. & 7.42 & $85 \cdot 86$ & 6 & 86.5 \\
\hline 4 & 0.093 & 186 & 050 & & 49 & .98 & .82 & 98 & 56 & 44 & 13 & 28 & $90 \cdot 26$ & 46 & 69 & 34 & $90 \cdot 45$ & $8 \cdot 20$ & 8.76 & $8 \cdot 30$ & $39 \cdot 69$ & 93 & 92 & 92.0 & $85 \cdot 41$ & $89 \cdot 35$ & 88.92 & $88 \cdot 74$ & $88 \cdot 38$ & 5 & 86 & 00 & $86 \cdot 31$ \\
\hline 5 & 0.115 & 199 & 0.096 & 090 & & 00. & 9 & $\cdot 14$ & & & 69 & & & & & & & & & & & & & 90 & & 86 & 86. & 86 & 85 & & 84. & & $85: 3$ \\
\hline 6 & 0.102 & 0.102 & 0.095 & 096 & $0 \cdot 100$ & & $93 \cdot 35$ & 83 & 54 & 3 & 90 & 18 & 50 & 63 & 86 & $90 \cdot 44$ & $89 \cdot 78$ & 17.06 & $6 \cdot 95$ & 88.65 & 87.91 & 91.72 & 7 & 90 & 84. & $86 \cdot 42$ & $86 \cdot 20$ & $86 \cdot 56$ & 85.9 & $5 \cdot 30$ & $86 \cdot 16$ & 85 & 35.7 \\
\hline 7 & 0.08 & 882 & 073 & 64 & 177 & 0.070 & & 07 & & & 54 & & & & & & & & & & & & & 93 & 85 & 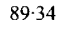 & & 88 & 87 & & & & 86 \\
\hline 8 & 0.115 & 07 & 0 & 19 & & 21 & $0 \cdot 107$ & & 93.99 & 3 & 6 & & & & & & & & & & 80.7 & & & 8 & 84 & 86 & 8 & 85 & 85 & 32 & 85.6 & $85 \cdot 1$ & 35 \\
\hline 9 & 0.1 & 126 & 119 & 23 & 131 & 124 & 0.112 & 63 & & 4 & 08 & 46 & $\varepsilon$ & ) & ) 32 & 90.17 & & 3. & 88 & $92^{\circ}$ & 87 & 89. & 77 & 90. & 82 & 85. & $85 \cdot 34$ & 85.69 & 85. & 4 & 44.44 & & 84.8 \\
\hline & 0.138 & & 0 & & & & & & 0 & & & & & & & & & & & & & & & & & & & & & & & & \\
\hline & & & & & & & 101 & & 6 & 0.1 & & $97 \cdot 38$ & 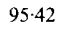 & 77 & 9 & $93 \cdot 49$ & $92 \cdot 93$ & 91.8 & 91.08 & 90. & $89 \cdot 6$ & 91.82 & 6 & 92 & 11 & 88 & 3 & $87 \cdot 90$ & 88 & 6.99 & $\cdot 15$ & $86 \cdot$ & 86.8 \\
\hline 12 & 0.098 & & 0 & 93 & & & & 197 & 02 & 0.114 & 0.027 & & $96 \cdot 13$ & & & 100 & & . & . & & $90 \cdot 16$ & $92 \cdot 28$ & 2 & 92 & $85 \cdot 32$ & & 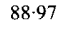 & 88 & 87. & & & & \\
\hline & & & & & & & & & & & & & & & & & & & & & & & & & & & & & & & & $86 \cdot 0$ & $86 \cdot 38$ \\
\hline & 0.098 & & 0.10 & & & & & & & 6 & & 0.047 & 0 & & $93 \cdot 28$ & 94.08 & & & & & & 12 & & 92 & $84 \cdot 55$ & 88 & 22 & 87.46 & $86 \cdot 29$ & 6.82 & 15 & 86.93 & 35 \\
\hline & 0.102 & & & & & & & & & & & & ( & & & 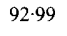 & & & & & & & & & & & & & & & & & \\
\hline & 0.095 & & & & & 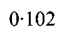 & & & & & & 0 & & & & & & & & & & 92.53 & 92.03 & $93 \cdot 74$ & $85 \cdot 36$ & 89 & 05 & 88.1 & 88.06 & 88.39 & 87.56 & 87.29 & 60 \\
\hline
\end{tabular}




\section{Table 2 (cont.)}

\begin{tabular}{|c|c|c|c|c|c|c|c|c|c|c|c|c|c|c|c|c|c|c|c|c|c|c|c|c|c|c|c|c|c|c|c|c|c|}
\hline & - & & & & & & 7 & $\mathbf{0}$ & & & 11 & & & 1 & 15 & 0 & & & & & & 2 & 3 & 24 & & & & & 9 & & & 32 & \\
\hline & 06 & & & & 01 & 10 & & & 116 & 25 & 74 & & & & 0.081 & 16 & & & & & & .81 & .77 & 22 & 4.37 & 88.04 & 81 & 10 & 5.56 & 82 & 5.92 & $6 \cdot 15$ & $85 \cdot 64$ \\
\hline & 118 & & & & & & & & 29 & & . & & & & & 065 & 070 & & & & & & & & & 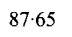 & & 0 & 13 & 50 & 9 & $5 \cdot 61$ & 0 \\
\hline & 142 & & & & & & & & 119 & 25 & 95 & 994 & & & 103 & 073 & 088 & & & & 53 & $9 \cdot 62$ & 0.12 & 25 & 92 & 87.24 & 87.07 & 59 & 60 & 85 & $86 \cdot 20$ & 6.13 & 85.01 \\
\hline & 136 & & & & & & & & & & & & & & 0 & 120 & & & 0.135 & & & 0.56 & 9 & & & & & 62 & $85 \cdot 47$ & & 96 & 3.62 & 3.5 \\
\hline & 133 & & & & & 32 & & & 132 & 51 & . & 105 & 118 & 8 & $0 \cdot 111$ & 114 & 118 & 128 & 148 & 0.078 & & 90.01 & $9 \cdot 75$ & 90 & 78 & 2 & 85. & 30 & 8 & 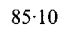 & 83. & 3 & $83 \cdot 93$ \\
\hline & 884 & & & & & 88 & & & & & & & & & 0.084 & 070 & & & 112 & 01 & $0 \cdot 107$ & & $95 \cdot 96$ & 9 & & 3 & 88.78 & & & & & & \\
\hline & 095 & & & & & 192 & & & 110 & 90 & 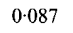 & 818 & & 4 & .094 & 084 & 098 & & 106 & $0.10^{3}$ & 0.110 & 0.042 & & 0326 & $86 \cdot 22$ & 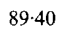 & 88 & 8 & 88.3 & & 87.7 & 17.8 & 87.0 \\
\hline & 880 & 7 & & & & & & & 104 & & 84 & & & & & 065 & & & $0 \cdot 104$ & 0.101 & 104 & 0.062 & 0.066 & & $84 \cdot 18$ & 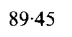 & $89 \cdot 04$ & 87 & & & 87.22 & 86.97 & \\
\hline & 184 & & & & & & & & & & & & & & & & & & & & & 0.162 & 152 & 0.178 & & & & & & & $82 \cdot 3$ & & \\
\hline & 138 & 123 & & 5 & 149 & 50 & & 147 & 0.152 & 55 & 0.127 & 20 & 137 & 0.127 & 0 & 114 & 136 & & 140 & 0.155 & 6157 & 0.115 & 0.114 & $0 \cdot 114$ & 79 & & $98 \cdot 75$ & & & 95.92 & $89 \cdot 14$ & & \\
\hline & 0.14 & & & & & & & & & & & & & & & & & & & & & & & $0 \cdot 118$ & 180 & 0.013 & & & & 95 & 88. & $88 \cdot 80$ & 88.08 \\
\hline & 151 & 36 & & 122 & 0 & $48 \quad$ & & 0.159 & 0.163 & 168 & 0 & 124 & 0.145 & 4 & 0 & 0.129 & .14 & & 0.48 & 0.160 & & 0.127 & & 0 . & 90 & 45 & 0.044 & & & & & & \\
\hline & 0.139 & & & & & & & & & & 30 & & & 0.151 & & & & & $0 \cdot 148$ & $0 \cdot 162$ & & $0 \cdot 122$ & $0 \cdot 127$ & $0 \cdot 13$ & 0.208 & 0.03 & 0.035 & 0.034 & & 95. & 88.2 & $88 \cdot 19$ & 77.98 \\
\hline & 152 & 135 & & & & & & & & & 0 & & & $0 \cdot 145$ & & & & & & & & & & & & & 44 & 48 & & & $89 \cdot 23$ & $9 \cdot 36$ & \\
\hline & 165 & & & & & 53 & & & & 32 & 0.153 & & & $0 \cdot 141$ & 0. & & & & & $0 \cdot 180$ & & $0 \cdot 120$ & 0.134 & 0.1 & 0.201 & 0.11 & 0 & 0.136 & 28 & & & & \\
\hline & $0 \cdot 16$ & & & & & & & & & & & & & & & & & & & & & 0.129 & & 0.143 & 99 & 12 & 21 & 143 & 129 & 115 & 0.018 & & $93 \cdot 60$ \\
\hline & & & & & & & & & & & & & & & & & & & & 0106 & & & & & 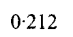 & 0 & & & & & & 0067 & \\
\hline
\end{tabular}




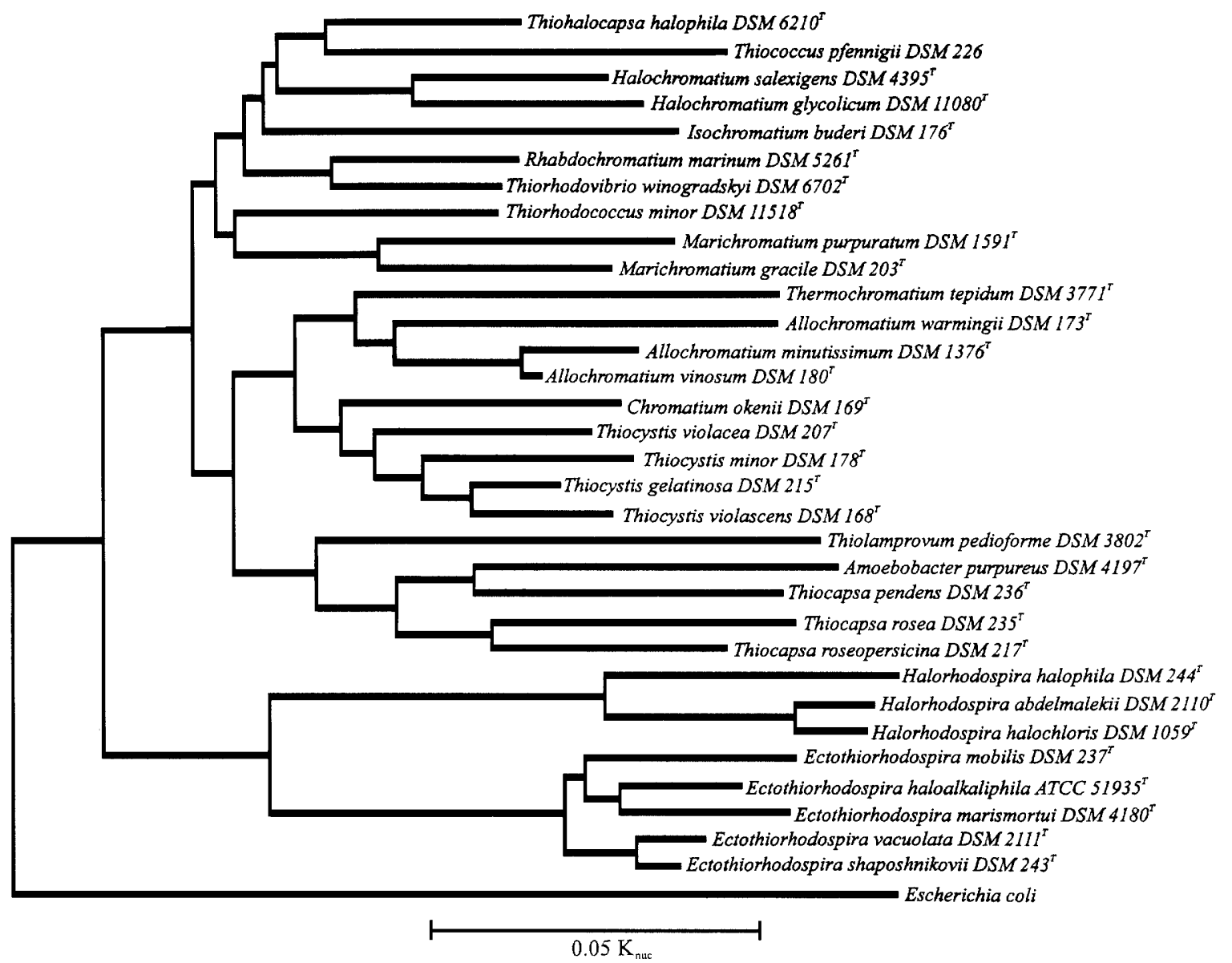

Fig. 1. Phylogenetic tree showing the relationships of the investigated type strains of Chromatium species and related purple sulfur bacteria. Derived from the distance matrix (Table 2) and calculated as indicated in Methods.

isolates from coastal environments do grow in the presence of low concentrations of salt but do not require salt for growth (R. Guyoneaud \& P. Caumette, personal communication).

\section{DISCUSSION}

The available 16S rDNA sequence information of Ectothiorhodospiraceae (Imhoff \& Süling, 1996) and Chromatiaceae species (DeWeerd et al., 1990; Wahlund et al., 1991; Caumette et al., 1997; Guyoneaud et al., 1997, 1998; and this work) support the separation of these two families (Imhoff, 1984a) and at the same time demonstrate the inconsistency of the present taxonomic classification of the Chromatiaceae with their genetic relationships. Most of the morphological and physiological properties, upon which the current taxonomy is based, have to be regarded as being of minor importance in support of a genetically oriented taxonomic classification, while others, so far much less considered properties, supposedly are of higher significance in this regard. The differential characteristics of the genera and species of the Chromatiaceae are summarized in Table 3, and are discussed below.

\section{Morphological properties}

The principal classification schemes of Chromatiaceae genera use cell form, motility by flagella and presence of gas vesicles as key properties (Imhoff \& Trüper, 1982 ;Pfennig \& Trüper, 1974, 1989). Though it would be an exaggeration to state that these properties have no taxonomic meaning, it is clear that they are insufficient taxonomic characteristics and not sufficient to decide on the assignment of bacteria to a particular genus. Non-motile spherical purple sulfur bacteria without gas vesicles, for example, had been united within the genus Thiocapsa. However, genetic relationships indicate that two of the three known species (Thiocapsa halophila and Thiocapsa pfennigii) are not at all related to the type species of this genus, which is Thiocapsa roseopersicina. On the other hand, some of the spherical cells containing gas vesicles (former Amoebobacter species) are now also recognized as members of this genus, indicating that the presence of gas vesicles should no longer be a genus determinative property either. Nonetheless, one of the major phylogenetic clusters of Chromatiaceae is constituted out of spherical cells without flagellar movement and with or without gas vesicles (Fig. 1; Guyoneaud et al., 1998). 
Table 3. Differential characteristics of genera and species of the Chromatiaceae family

\begin{tabular}{|c|c|c|c|c|c|c|c|c|}
\hline $\begin{array}{l}\text { Genus and new } \\
\text { species name }\end{array}$ & Motile & $\begin{array}{c}\text { Gas } \\
\text { vesicles }\end{array}$ & $\begin{array}{l}\text { Cell form } \\
\text { and size } \\
(\mu \mathrm{m})\end{array}$ & $\begin{array}{l}\text { Optimum } \\
\text { salinity } \\
(\%)\end{array}$ & $T_{\text {opt }}$ & $\begin{array}{l}\text { Vitamins } \\
\text { required }\end{array}$ & $\begin{array}{l}\mathrm{G}+\mathrm{C} \\
\text { content } \\
(\mathrm{mol} \%)\end{array}$ & $\begin{array}{l}\text { Chemoauto- } \\
\text { trophy }\end{array}$ \\
\hline $\begin{array}{l}\text { Halochromatium } \\
\text { Halochromatium salexigens } \\
\text { Halochromatium glycolicum }\end{array}$ & Yes & No & $\begin{array}{c}\text { Rod } \\
2 \cdot 0-2 \cdot 5 \\
0 \cdot 8-1 \cdot 0\end{array}$ & $\begin{array}{c}10 \\
2 \cdot 5-6 \cdot 0\end{array}$ & $\begin{array}{l}20-30 \\
30-35\end{array}$ & $\begin{array}{c}\mathrm{B}_{12} \\
\text { None }\end{array}$ & $\begin{array}{l}64 \cdot 6 \\
66 \cdot 3\end{array}$ & $\begin{array}{l}\text { Yes } \\
\text { Yes }\end{array}$ \\
\hline $\begin{array}{l}\text { Thiohalocapsa } \\
\text { Thiohaloc apsa halophila }\end{array}$ & No & No & $\begin{array}{l}\text { Sphere } \\
1 \cdot 5-2 \cdot 5\end{array}$ & $5-7$ & $20-30$ & $\mathrm{~B}_{12}$ & $65 \cdot 9-66 \cdot 6$ & Yes \\
\hline $\begin{array}{l}\text { Thiococcus } \\
\text { Thiococcus pfennigii }\end{array}$ & No & No & $\begin{array}{l}\text { Sphere } \\
1 \cdot 2-1 \cdot 5\end{array}$ & $1-2$ & $20-35$ & None & $69 \cdot 4-69 \cdot 9$ & No \\
\hline $\begin{array}{l}\text { Rhabdochromatium } \\
\text { Rhabdochromatium marinum }\end{array}$ & Yes & No & $\begin{array}{c}\text { Rod } \\
1 \cdot 5-1 \cdot 7\end{array}$ & $1 \cdot 5-5$ & 30 & None & $60 \cdot 4$ & No \\
\hline $\begin{array}{l}\text { Isochromatium } \\
\text { Isochromatium buderi }\end{array}$ & Yes & No & $\begin{array}{c}\text { Rod } \\
3 \cdot 5-4 \cdot 5\end{array}$ & $1-3$ & $25-30$ & $\mathrm{~B}_{12}$ & $62 \cdot 2-62 \cdot 8$ & No \\
\hline $\begin{array}{l}\text { Thiorhodococcus } \\
\text { Thiorhodococcus minor }\end{array}$ & Yes & No & $\begin{array}{l}\text { Sphere } \\
1 \cdot 0-2 \cdot 0\end{array}$ & 2 & $30-35$ & None & $66 \cdot 9$ & Yes \\
\hline $\begin{array}{l}\text { Marichromatium } \\
\text { Marichromatium gracile } \\
\text { Marichromatium purpuratum }\end{array}$ & Yes & No & $\begin{array}{l}\text { Rod } \\
1 \cdot 0-1 \cdot 3 \\
1 \cdot 2-1 \cdot 7\end{array}$ & $\begin{array}{l}2-3 \\
2-7\end{array}$ & $\begin{array}{l}30-35 \\
25-30\end{array}$ & $\begin{array}{c}\text { None } \\
0\end{array}$ & $\begin{array}{l}68 \cdot 9-70 \cdot 4 \\
68 \cdot 9\end{array}$ & $\begin{array}{c}\text { Yes } \\
\text { o }\end{array}$ \\
\hline $\begin{array}{l}\text { Thiorhodovibrio } \\
\text { Thiorhodovibrio winogradskyi }\end{array}$ & Yes & No & $\begin{array}{c}\text { Spiral } \\
0 \cdot 8-1 \cdot 4\end{array}$ & $2-3$ & 33 & None & $61 \cdot 0-62 \cdot 4$ & Yes \\
\hline $\begin{array}{l}\text { Allochromatium } \\
\text { Allochromatium vinosum } \\
\text { Allochromatium minutissimum } \\
\text { Allochromatium warmingii }\end{array}$ & Yes & No & $\begin{array}{l}\text { Rod } \\
2 \cdot 0 \\
1 \cdot 0-1 \cdot 2 \\
3 \cdot 5-4 \cdot 0\end{array}$ & $\begin{array}{l}\text { o } \\
\text { None } \\
\text { None }\end{array}$ & $\begin{array}{l}30-35 \\
30-35 \\
25-30\end{array}$ & $\begin{array}{l}\text { None } \\
\text { None } \\
B_{12}\end{array}$ & $\begin{array}{l}61 \cdot 3-66 \cdot 3 \\
63 \cdot 7 \\
55 \cdot 1-60 \cdot 2\end{array}$ & $\begin{array}{l}\text { Yes } \\
\text { Yes } \\
\text { No }\end{array}$ \\
\hline $\begin{array}{l}\text { Thermochromatium } \\
\text { Thermochromatium tepidum }\end{array}$ & Yes & No & $\begin{array}{l}\text { Rod } \\
1 \cdot 0-2 \cdot 0\end{array}$ & None & $48-50$ & None & $61 \cdot 5$ & No \\
\hline $\begin{array}{l}\text { Chromatium } \\
\text { Chromatium okenii } \\
\text { Chromatium weissei }\end{array}$ & Yes & No & $\begin{array}{l}\text { Rod } \\
4 \cdot 5-6 \cdot 0 \\
3 \cdot 5-4 \cdot 0\end{array}$ & $\begin{array}{l}\text { None } \\
\text { None }\end{array}$ & $\begin{array}{l}25-30 \\
25-30\end{array}$ & $\begin{array}{l}\mathrm{B}_{12} \\
\mathrm{~B}_{12}\end{array}$ & $\begin{array}{l}48 \cdot 0-50 \cdot 0 \\
48 \cdot 0-50 \cdot 0\end{array}$ & $\begin{array}{l}\text { No } \\
\text { No }\end{array}$ \\
\hline $\begin{array}{l}\text { Thiocystis } \\
\text { Thiocystis gelatinosa } \\
\text { Thiocystis minor } \\
\text { Thiocystis violacea } \\
\text { Thiocystis violascens }\end{array}$ & Yes & No & $\begin{array}{l}\text { Sphere/rod } \\
3 \cdot 0 \\
2 \cdot 0 \\
2 \cdot 5-3 \cdot 5 \\
2 \cdot 0\end{array}$ & $\begin{array}{l}\text { None } \\
\text { None } \\
\text { o } \\
0\end{array}$ & $\begin{array}{l}30 \\
30 \\
25-35 \\
30-35\end{array}$ & $\begin{array}{l}\text { None } \\
\text { None } \\
\text { None } \\
\text { None }\end{array}$ & $\begin{array}{l}61 \cdot 3 \\
62 \cdot 2 \\
62 \cdot 8-67 \cdot 9 \\
61 \cdot 8-64 \cdot 3\end{array}$ & $\begin{array}{l}\text { Yes } \\
\text { Yes } \\
\text { Yes } \\
\text { Yes }\end{array}$ \\
\hline $\begin{array}{l}\text { Thiocapsa } \\
\text { Thiocapsa roseopersicina } \\
\text { Thiocapsa rosea } \\
\text { Thiocapsa pendens }\end{array}$ & No & No & $\begin{array}{l}\text { Sphere } \\
1 \cdot 2-3 \cdot 0 \\
2 \cdot 0-3 \cdot 0 \\
1 \cdot 5-2 \cdot 5\end{array}$ & $\begin{array}{l}\text { o } \\
\text { None } \\
\text { None }\end{array}$ & $\begin{array}{l}20-35 \\
20-35 \\
20-35\end{array}$ & $\begin{array}{l}\text { None } \\
\mathrm{B}_{12} \\
\mathrm{~B}_{12}\end{array}$ & $\begin{array}{l}63 \cdot 3-66 \cdot 3 \\
64 \cdot 3 \\
65 \cdot 3\end{array}$ & $\begin{array}{l}\text { Yes } \\
\text { Yes } \\
\text { No }\end{array}$ \\
\hline $\begin{array}{l}\text { Thiolamprovum } \\
\text { Thiolamprovum pedioforme }\end{array}$ & No & Yes & $\begin{array}{l}\text { Sphere } \\
2 \cdot 0\end{array}$ & None & 37 & $\left(\mathrm{~B}_{12}\right)$ & $65 \cdot 5$ & Yes \\
\hline $\begin{array}{l}\text { Amoebobacter } \\
\text { Amoebobacter purpureus }\end{array}$ & No & Yes & $\begin{array}{l}\text { Sphere } \\
1 \cdot 9-2 \cdot 3\end{array}$ & None & $23-25$ & o & $63 \cdot 5$ & Yes \\
\hline $\begin{array}{l}\text { Thiodictyon } \\
\text { Thiodictyon elegans } \\
\text { Thiodictyon bacillosum }\end{array}$ & No & Yes & $\begin{array}{l}\text { Rod } \\
1 \cdot 5-2 \cdot 0 \\
1 \cdot 5-2 \cdot 0\end{array}$ & $\begin{array}{l}\text { None } \\
\text { None }\end{array}$ & $\begin{array}{l}20-25 \\
20-30\end{array}$ & $\begin{array}{l}\text { None } \\
\text { None }\end{array}$ & $\begin{array}{l}65 \cdot 3 \\
66 \cdot 3\end{array}$ & $\begin{array}{l}\text { No } \\
\text { No }\end{array}$ \\
\hline $\begin{array}{l}\text { Lamprobacter } \\
\text { Lamprobacter modestohalophilus }\end{array}$ & Yes & Yes & $\begin{array}{c}\text { Rod } \\
2 \cdot 0-2 \cdot 5\end{array}$ & $1-2$ & $25-27$ & $\mathrm{~B}_{12}$ & $64 \cdot 0$ & Yes \\
\hline $\begin{array}{l}\text { Lamprocystis } \\
\text { Lamprocystis roseopersicina }\end{array}$ & Yes & Yes & $\begin{array}{l}\text { Sphere } \\
3 \cdot 0-3 \cdot 5\end{array}$ & None & $20-30$ & None & $63 \cdot 8$ & No \\
\hline $\begin{array}{l}\text { Thiospirillum } \\
\text { Thiospirillum jenense }\end{array}$ & Yes & No & $\begin{array}{l}\text { Spiral } \\
2 \cdot 5-4 \cdot 5\end{array}$ & None & $20-25$ & $\mathrm{~B}_{12}$ & $45 \cdot 5$ & No \\
\hline $\begin{array}{l}\text { Thiopedia } \\
\text { Thiopedia rosea }\end{array}$ & No & Yes & $\begin{array}{l}\text { Sphere } \\
1 \cdot 0-2 \cdot 0\end{array}$ & None & 20 & $\mathrm{~B}_{12}$ & $62 \cdot 5-63 \cdot 5$ & No \\
\hline
\end{tabular}




\section{Physiological properties}

Physiological properties always have been important characteristics in taxonomic considerations, although their taxonomic significance is ambiguous. On the one hand, physiological properties of the Chromatiaceae are quite conservative in regard to the use of sulfur sources and the restricted use of organic carbon sources. All species are able to grow photoautotrophically under anoxic conditions in the light using sulfide or elemental sulfur as an electron donor. On the other hand, we distinguish two major physiological groups, versatile and specialized species. The specialized species depend on strictly anoxic conditions and are obligately phototrophic. Sulfide is required, thiosulfate and hydrogen are not used as electron donors. Only acetate and pyruvate (or propionate) are photoassimilated in the presence of sulfide and $\mathrm{CO}_{2}$. These bacteria do not grow with organic electron donors and chemotrophic growth is not possible. None of these species assimilates sulfate as a sulfur source. Among these species are Chromatium okenii, Chromatium weissei, Chromatium warmingii, Chromatium buderi, Thiospirillum jenense and Thiocapsa pfennigii. The versatile species photoassimilate a greater number of organic substrates. Most of them are able to grow with sulfate and in the absence of reduced sulfur sources with organic substrates as electron donors for photosynthesis. Some species even grow as chemoautotrophs, and a few species can grow chemoheterotrophically in addition (Gorlenko, 1974; Kondratieva et al., 1976; Kämpf \& Pfennig, 1980, 1986). Among these species are several small-celled Chromatium species, Thiocystis violacea, Thiocapsa roseopersicina, Thiocapsa rosea (formerly Amoebobacter roseus), Thiocapsa pendens (formerly Amoebobacter pendens) and Lamprobacter modestohalophilus.

Although some specialized species, such as Chromatium okenii, Chromatium buderi and Thiocapsa pfennigii form well-separated genetic lines, others like Chromatium warmingii are moderately related to the versatile Chromatium vinosum, justifying their inclusion into one and the same genus. Therefore, at present the versatility versus specialization of the species appears not to be a good taxonomic criterion.

\section{Salt relationships}

Though salt dependence has been used already in the past to distinguish between species and even genera, the phylogenetic and taxonomic importance of this property has so far not been fully recognized. Major phylogenetic branches within the Chromatiaceae can be distinguished on the basis of their salt requirement (Fig. 1, Table 2), one exclusively containing marine and halophilic species, the other primarily freshwater isolates. This implies principally that a separate evolutionary development has occurred in the marine and in the freshwater environments and that therefore the salt response should be considered as an important taxonomic criterion. The salt requirement apparently is of general taxonomic importance in phototrophic bacteria and already has been considered in the taxonomy of purple non-sulfur bacteria and Ectothiorhodospiraceae. It proved to be of relevance to distinguish the genera Halorhodospira and Ectothiorhodospira (Imhoff \& Süling, 1996), Rhodovulum and Rhodobacter (Hiraishi \& Ueda, 1994) and also genera of the spiral-shaped purple non-sulfur $\alpha$ Proteobacteria, the former Rhodospirillum species (Imhoff et al., 1998). Furthermore, phylogenetic relationships of the Chlorobiaceae indicate that salt relationships may be a useful criterion also for these bacteria (Overmann \& Tuschak, 1997).

Genetic relationships of the Chromatiaceae (Fig. 1, Table 2) revealed the obvious divergence of freshwater and saltwater bacteria. In particular the so far known genera Chromatium and Thiocapsa have representatives in both of these phylogenetic branches. As a consequence thereof, the salt relation should be considered as property for characterization of 'genetically defined' genera. Thus, both the genetic relationships and the salt responses enable differentiation of the halophilic Chromatium species Chromatium salexigens and Chromatium glycolicum from the marine species Chromatium gracile and Chromatium purpuratum, and from the freshwater species of Chromatium vinosum and relatives. Although salt relationships obviously are important properties for the taxonomic characterization of Chromatiaceae, in a few species the congruence between their phylogenetic position and their salt response requires further attention. Species such as Chromatium vinosum and Thiocapsa roseopersicina have been reported to be found in freshwater, brackish water and marine habitats. In regard to Thiocapsa roseopersicina, sequence relationships indicate that a number of strains isolated from the marine environment and assigned to this species could be distinguished at the species level (Guyoneaud et al., 1998). These bacteria behave indifferently to low salt concentrations and may be poorly adapted to the marine environment, being halotolerant but not halophilic. In regard to Chromatium vinosum the situation is unclear at present. Large differences in the $\mathrm{G}+\mathrm{C}$ content of the DNA of strains assigned to this species $(61 \cdot 3-66 \cdot 3 \mathrm{~mol} \%)$ may indicate genetic heterogeneity. So far, clear proof of identity of various isolates from marine habitats assigned to Chromatium vinosum on the species level is lacking. Further studies will be needed to determine whether differences in the $\mathrm{G}+\mathrm{C}$ content are correlated with the occurrence of these bacteria in marine or freshwater environments.

\section{DNA base ratio}

The DNA base ratio, expressed as the $\mathrm{G}+\mathrm{C}$ content, which always has been regarded as a taxonomically important parameter, is gaining new attention in view of a genetically oriented taxonomic system. It has been found to be highly variable in some of the known Chromatiaceae genera (e.g. values from $48 \cdot 0$ to 
$70 \cdot 4 \mathrm{~mol} \% \mathrm{G}+\mathrm{C}$ in the genus Chromatium). However, it is assumed that to a large extent the intrageneric and also the intraspecies variability represents the nonphylogenetic nature of the current taxonomic system and misclassification of strains, respectively. A more natural system would be expected to group bacteria together that have much less variation in their $\mathrm{G}+\mathrm{C}$ content. Indeed, genetically closely related species of the Chromatiaceae in general have a quite narrow range of their $\mathrm{G}+\mathrm{C}$ content, which is approximately 63-66 mol\% in the Thiocapsa/Amoebobacter cluster, between 61-64 mol \% in the proposed Thiocystis group (with the exception of a few strains of Thiocystis violacea), at $69-70 \mathrm{~mol} \%$ in the proposed Marichromatium species and at $6466 \mathrm{~mol} \%$ in the proposed Halochromatium species. In the true Chromatium species it is as low as $48-50 \mathrm{~mol} \%$. A few species, Chromatium vinosum $(61 \cdot 3-66 \cdot 3 \mathrm{~mol} \%)$, Chromatium warmingii $(55 \cdot 1-60 \cdot 2 \mathrm{~mol} \%)$ and Thiocystis violacea $(62.8-67.9 \mathrm{~mol} \%)$ have surprisingly high intraspecies variation of their $\mathrm{G}+\mathrm{C}$ content. Further studies are needed to clarify whether analytical problems have caused these variations or misclassification of some strains is indicated. Variation at the intraspecies level of more than 5 and up to $10 \mathrm{~mol} \% \mathrm{G}+\mathrm{C}$ content of the DNA is by far beyond an acceptable level of natural variation within bacteria as closely related as to justify their classification into one and the same species.

\section{Temperature response}

The temperature response of many species is not wellresolved and in most cases probably of minor significance for taxonomic purposes. However, as far as the temperature extremes are concerned, specific adaptation mechanisms are involved, specific environmental niches are inhabited and a different evolutionary background can be expected. Therefore, it is very well indicated to taxonomically consider the successful adaptation to the extremes of temperature. The only species of the Chromatiaceae so far known, which exhibits a very high optimum temperature response is Chromatium tepidum (optimum at $48-50^{\circ} \mathrm{C}$ ), which also is genetically distinct from other species within the cluster of freshwater species.

\section{Molecular parameters}

Though only scattered information is available on fatty acid and quinone composition of Chromatiaceae, it appears that these components, which are wellaccepted tools for identification and taxonomic differentiation of phototrophic bacteria (Imhoff, 1984b, 1991; Imhoff \& Bias-Imhoff, 1995; Thiemann \& Imhoff, 1996), show minor variation and are of low significance for taxonomic differentiation within the Chromatiaceae (Imhoff \& Bias-Imhoff, 1995). However, the polar lipid composition, that has been analysed so far only in several freshwater species, despite surprisingly similar patterns in genetically related species, shows significant variation between groups of species (J. F. Imhoff, unpublished results). For example, Chromatium vinosum and Chromatium warmingii, two species of the proposed new genus Allochromatium, contain the same lipids. Their lipid composition is different from a second group of species, the proposed members of the genus Thiocystis (Chromatium minus, Chromatium violascens and the two known Thiocystis species), which also show uniformity in this property. In contrast, the lipid composition of Thiocapsa pfennigii is different from all other so far analysed phototrophic purple bacteria ( $\mathrm{J}$. F. Imhoff, unpublished results). Thus, the pattern of polar lipid composition, as far as known, is congruent with the sequence-based similarity of these bacteria and may well turn out to be a significant property to distinguish genetically related groups of Chromatiaceae in the future. More analytical data are required to support this concept.

Despite these first attempts to define phenotypic properties that are congruent with the genetic relationships of the purple sulfur bacteria, the search for more of such properties must be continued and those properties that are of relevance must be analysed in all known species. The differentiation of the Chromatiaceae species on the basis of some diagnostic properties is shown in Table 3.

\section{Proposed taxonomic changes}

On the basis of their genetic relationships and in consideration of the preceding discussion on the relevance of various phenotypic properties, the following taxonomic changes are proposed:

(1) Chromatium minus and Chromatium violascens are most closely related to Thiocystis gelatinosa, but different from this bacterium at the species level. Therefore, we propose to transfer these species to the genus Thiocystis with the new names Thiocystis minor comb. nov. and Thiocystis violascens comb. nov., respectively.

(2) Chromatium vinosum, Chromatium minutissimum and Chromatium warmingii are closely related species that should be placed into a new genus, because of their genetic distance from Chromatium okenii. Because Chromatium vinosum is among the best-studied purple sulfur bacteria and the name Chromatium is very much associated with this species, we propose the name Allochromatium gen. nov. ("the other Chromatium') for the new genus, with Allochromatium vinosum comb. nov. as the type species and Allochromatium minutissimum comb. nov. and Allochromatium warmingii comb. nov. as additional species of the genus.

(3) Because Chromatium tepidum quite obviously can not be retained within the genus Chromatium and it is neither specifically related to Thiocystis nor to Allochromatium, it should also be placed in a new genus. The $16 \mathrm{~S}$ rDNA sequence data justify this conclusion. Chromatium tepidum is the only thermophilic isolate of the purple sulfur bacteria described so 
far. Although it is not well-established whether and to what extent the temperature response is of phylogenetic and taxonomic significance, we regard the thermophilic nature and high temperature optimum of this species as a valid criterion for genus differentiation and propose Thermochromatium gen. nov. as the new genus name and Thermochromatium tepidum comb. nov. as the new name for this species.

(4) Chromatium salexigens and Chromatium glycolicum shall be transferred to the new genus Halochromatium gen. nov. because of their extended salt dependence and salt tolerance, which is the highest within the Chromatiaceae, with Halochromatium salexigens comb. nov. as the type species and Halochromatium glycolicum comb. nov. as an additional species.

(5) Chromatium gracile and Chromatium purpuratum are transferred to the new genus Marichromatium. The name is proposed according to the marine origin and the moderate salt dependence that is characteristically found in typical marine bacteria. The new names Marichromatium gracile comb. nov. and Marichromatium purpuratum comb. nov. are proposed for these two species. Marichromatium gracile is the proposed type species.

(6) By its intracytoplasmic membrane system and its pigment composition, Thiocapsa pfennigii is unique among the family Chromatiaceae (Eimhjellen et al., 1967; Eimhjellen, 1970). Certainly, it can no longer be regarded as a species of the genus Thiocapsa, because it is significantly different from this genus on the basis of the available genetic sequence information and belongs to the cluster of the halophilic Chromatiaceae species. Its phenotypic traits together with the results on its genetic relationships to other Chromatiaceae led us to consider this species as a separate genus. According to Rule $33 \mathrm{c}$ of the International Code of Nomenclature of Bacteria (Lapage et al., 1992), we propose to revive the genus name Thiococcus Eimhjellen et al. 1967 and to transfer Thiocapsa pfennigii to Thiococcus pfennigii gen. nom. rev., comb. nov. The name Thiococcus, originally used by Eimhjellen et al. (1967) to describe this bacterium, was not validly published and is illegitimate and therefore was not included into the Approved Lists of Bacterial Names.

(7) Phylogenetically, the bacterium described as Thiocapsa halophila is not related to the genus Thiocapsa and is most similar on the basis of its $16 \mathrm{~S}$ rDNA sequence to Thiocapsa pfennigii, Chromatium salexigens and Chromatium glycolicum (Fig. 1). Because of significant genotypic and phenotypic properties to these bacteria, it should be recognized as a separate and new genus. Thiohalocapsa gen. nov. is proposed as the new genus name and Thiocapsa halophila is transferred to the new genus as Thiohalocapsa halophila comb. nov.

(8) Chromatium buderi is a marine species of the Chromatiaceae. However, according to its 16S rDNA sequence it is dissimilar to any of the other described species of this branch to a degree that suggests its recognition as a separate genus for which the name Isochromatium is proposed. Chromatium buderi is transferred to this new genus as Isochromatium buderi comb. nov.

\section{Emended description of the genus Chromatium Perty $1852,174^{\text {AL }}$}

Chromatium (Chro.ma'ti.um. Gr. n. chroma colour; M.L. neut. n. Chromatium the one which is coloured).

Cells are straight or slightly curved rods, more than $3 \mu \mathrm{m}$ wide, motile by a polar tuft of flagella. Cells occur singly or in pairs. Multiply by binary fission. Gram-negative. Contain internal photosynthetic membrane systems of vesicular type in which the photosynthetic pigments bacteriochlorophyll $a$ and carotenoids are located. Obligately phototrophic, strictly anaerobic, require sulfide-reduced media. Under anoxic conditions capable of photolithoautotrophic growth with sulfide or elemental sulfur as electron donor. Elemental sulfur is formed as an intermediate oxidation product and stored in the form of highly refractile globules inside the cells. Sulfate is the ultimate oxidation product. In the presence of sulfide and bicarbonate, able to photoassimilate only a few simple organic compounds such as acetate and pyruvate. Assimilatory sulfate reduction is lacking. Vitamin $B_{12}$ is required. Mesophilic with optimal growth temperatures of $20-30^{\circ} \mathrm{C}$, freshwater bacteria without a distinct requirement for salt. Habitat: ditches, ponds and lakes with stagnant freshwater containing hydrogen sulfide and exposed to light. The $\mathrm{G}+\mathrm{C}$ content of the DNA is $48 \cdot 0-50 \cdot 0 \mathrm{~mol} \%(\mathrm{Bd})$. Type species is Chromatium okenii (Ehrenberg 1838, Perty $\left.1852,174^{\mathrm{AL}}\right)$. Most likely also Chromatium weisse $i$ is a species of this genus.

\section{Emended description of the genus Thiocystis Winogradsky $1888,60^{\mathrm{AL}}$}

Thiocystis (Thi.o.cys'tis. Gr. n. thios sulfur; Gr. n. cystis the bladder, a bag; M.L. fem. n. Thiocystis sulfur bag).

Cells are rod-shaped or ovoid to spherical, before cell division often diplococcus-shaped. Cells occur singly or in pairs, may grow in irregular aggregates surrounded by slime. Multiply by binary fission, motile by means of flagella. Gram-negative. Contains internal photosynthetic membrane systems of vesicular type in which the photosynthetic pigments bacteriochlorophyll $a$ and carotenoids are located. Under anoxic conditions, cells are capable of photolithoautotrophic growth with sulfide or sulfur as electron donor, thiosulfate may also be used. During sulfide oxidation, globules of elemental sulfur are transiently stored inside the cells. The final oxidation product is sulfate. In the presence of sulfide and bicarbonate, several simple organic substrates are photoassimilated. Facultatively chemoautotrophic or mixotrophic under micro-oxic to oxic conditions. Mesophilic bacteria 
with good growth at $25-35^{\circ} \mathrm{C}, \mathrm{pH} 6 \cdot 5-7 \cdot 6$. Principally freshwater bacteria, several of which may be found also in brackish and marine environments. Habitat: anoxic sulfide-containing water and mud of freshwater ponds and lakes as well as brackish water and marine environments exposed to light. The $\mathrm{G}+\mathrm{C}$ content of the DNA is $61 \cdot 3-67.9 \mathrm{~mol} \%(\mathrm{Bd})$. Type species is Thiocystis violacea Winogradsky $1888,65^{\mathrm{AL}}$. Other species are Thiocystis gelatinosa, Thiocystis minor and Thiocystis violascens.

\section{Description of Thiocystis minor comb. nov.}

Thiocystis minor (Chromatium minus Winogradsky 1888, 99 ${ }^{\mathrm{AL}}$ ) (mi'nor. L. fem. comp. adj. minor less, smaller). The description is the same as that for Chromatium minus (Winogradsky, 1888; Pfennig \& Trüper, 1989).

\section{Description of Thiocystis violascens comb. nov.}

Thiocystis violascens (Chromatium violascens Perty $1852,174^{\mathrm{AL}}$ ) (vi.o.las'cens. L. part. violascens becoming violet). The description is the same as that for Chromatium violascens (Perty, 1852; Pfennig \& Trüper, 1989).

\section{Description of Thiococcus gen. nom. rev.}

Thiococcus (Thi.o.coc'cus. Gr. n. thios sulfur; L. masc. n. coccus sphere; M.L. masc. n. Thiococcus sphere with sulfur). The genus name Thiococcus was proposed for this bacterium by Eimhjellen et al. (1967). However, this name has never been validly published and the organism was validly named Thiocapsa pfennigii (Eimhjellen, 1970; Approved Lists of Bacterial Names, 1980). The name Thiococcus is revived according to Rule $33 \mathrm{c}$ of the International Code of Nomenclature of Bacteria (Lapage et al., 1992).

Cells are spherical with diplococcus-shaped division stages. Multiply by binary fission. Gram-negative. Internal photosynthetic membrane system consisting of bundles of ribbonlike branched tubes continuous with the cytoplasmic membrane. Individual cells colourless. colour of cell suspensions yellowish to orange-brown. Photosynthetic pigments are bacteriochlorophyll $b$ and carotenoids. Obligately phototrophic and strictly anaerobic. Capable of photolithoautotrophic growth with sulfide and sulfur as electron donor. Elemental sulfur globules are transiently stored inside the cells, final oxidation product is sulfate. In the presence of sulfide and bicarbonate organic substrates are photoassimilated. Good growth at $20-35^{\circ} \mathrm{C}, \mathrm{pH} 6 \cdot 5-7 \cdot 5$. Salt is required for optimum growth. Habitat: brackish and marine waters and sediments containing hydrogen sulfide and exposed to the light. The $\mathrm{G}+\mathrm{C}$ content of the DNA is 69.4 $69.9 \mathrm{~mol} \%(\mathrm{Bd})$. Type species is Thiococcus pfennigii.

\section{Description of Thiococcus pfennigii comb. nov.}

Thiococcus pfennigii (Thiocapsa pfennigii Eimhjellen 1970, 193 ${ }^{\mathrm{AL}}$ ) (pfen.nig'i.i. M.L. gen. n. pfennigii of Pfennig; named after Norbert Pfennig, a German microbiologist). The description is the same as that for Thiocapsa pfennigii (Eimhjellen, 1970; Pfennig \& Trüper, 1989).

\section{Description of Thiohalocapsa gen. nov.}

Thiohalocapsa (Thi.o.ha.lo.cap'sa. Gr. n. thios sulfur; Gr. gen. n. halos of the salt; L. fem. n. capsa capsule; M.L. fem. n. Thiohalocapsa the sulfur capsule of the salt).

Cells are spherical, non-motile; multiply by binary fission. Individual cell surrounded by a strong slime capsule; cell aggregates may be formed. Gram-negative. Internal photosynthetic membrane system of vesicular type containing the photosynthetic pigments bacteriochlorophyll $a$ and carotenoids. Under anoxic conditions capable of photoautotrophic growth with sulfide, elemental sulfur and possibly other electron donors. During oxidation of sulfide, globules of elemental sulfur are transiently stored inside the cells, final oxidation product is sulfate. Assimilatory sulfate reduction lacking. Chemoautotrophic or chemoorganotrophic growth possible under micro-oxic to oxic conditions in the dark. Vitamin $\mathrm{B}_{12}$ is required. Mesophilic bacteria with good growth at $20-30{ }^{\circ} \mathrm{C}$, $\mathrm{pH} 6 \cdot 5-7 \cdot 5$. Elevated concentrations of sodium chloride are required for growth. Habitat: sulfide-containing waters and sediments of saltern and other coastal habitats with elevated salt concentrations and exposed to light. The $\mathrm{G}+\mathrm{C}$ content of the DNA is 65.9 $66.6 \mathrm{~mol} \%$ (Bd). Type species is Thiohalocapsa halophila.

\section{Description of Thiohalocapsa halophila comb. nov.}

Thiohalocapsa halophila (Thiocapsa halophila Caumette et al. 1991) (ha.lo'phi.la. Gr. n. hals salt; Gr. adj. philos loving; M.L. fem. adj. halophila saltloving). The description is the same as that for Thiocapsa halophila (Caumette et al., 1991).

\section{Description of Halochromatium gen. nov.}

Halochromatium (Ha.lo.chro.ma'ti.um. Gr. gen. n. halos of the salt; Chromatium a genus name; M.L. neut. n. Halochromatium the Chromatium of the salt). Cells are straight to slightly curved rods, multiply by binary fission; motile by polar flagella. Cells occur singly or in pairs. Gram-negative. Contain internal photosynthetic membrane systems of vesicular type in which the photosynthetic pigments bacteriochlorophyll $a$ and carotenoids are located. Under anoxic conditions in the light capable of photolithoautotrophic growth with sulfide or elemental sulfur as electron donor. Elemental sulfur is formed as an intermediate oxidation product and stored in the form of highly refractile globules inside the cells. 
Sulfate is the ultimate oxidation product. Hydrogen may be used as electron donor. In the presence of sulfide and bicarbonate organic substrates can be photoassimilated. Chemolithotrophic and chemoorganotrophic under micro-oxic conditions in the dark. Not capable of assimilatory sulfate reduction. Mesophilic with optimal growth temperatures of 20-35 ${ }^{\circ} \mathrm{C}$, optimum $\mathrm{pH} 7 \cdot 2-7 \cdot 6$. Elevated salt concentrations are required for growth. Habitat: reduced sediments in salinas, microbial mats in hypersaline environments, and coastal lagoons with elevated salt concentrations, which are exposed to light. The $\mathrm{G}+\mathrm{C}$ content of the DNA is $64 \cdot 6-66 \cdot 3 \mathrm{~mol} \%$ (Bd, HPLC). Type species is Halochromatium salexigens. An additional species is Halochromatium glycolicum.

\section{Description of Halochromatium salexigens comb.} nov.

Halochromatium salexigens (Chromatium salexigens Caumette et al. 1988) (sal.ex'i.gens. L. n. sal salt; L. v. exigo demanding, to demand; M.L. part. adj. salexigens salt-demanding). The description is the same as that for Chromatium salexigens (Caumette et al., 1988).

\section{Description of Halochromatium glycolicum comb. nov.}

Halochromatium glycolicum (Chromatium glycolicum Caumette et al. 1997) (gly.co'li.cum. M.L. neut. adj. glycolicum related to glycolate as a substrate). The description is the same as that for Chromatium glycolicum (Caumette et al., 1997).

\section{Description of Marichromatium gen. nov.}

Marichromatium (Ma.ri.chro.ma'ti.um. L. gen. n. maris of the sea; Chromatium a genus name; M.L. neut. n. Marichromatium the Chromatium of the sea, the truly marine Chromatium).

Cells are straight to slightly curved rods, multiply by binary fission, motile by polar flagella, occur singly or in pairs or may stick together and form clumps. Gramnegative. Contain internal photosynthetic membrane systems of vesicular type in which the photosynthetic pigments bacteriochlorophyll $a$ and carotenoids are located. Capable of photolithoautotrophic growth with sulfide or elemental sulfur as electron donor under anoxic conditions in the light. Elemental sulfur is formed as an intermediate oxidation product and stored in the form of highly refractile globules inside the cells. Sulfate is the ultimate oxidation product. Molecular hydrogen may be used as electron donor. In the presence of sulfide and bicarbonate, organic substrates can be photoassimilated. Chemolithotrophic and chemo-organotrophic growth may be possible under micro-oxic conditions in the dark. Mesophilic bacteria with optimal growth temperatures of $25-35^{\circ} \mathrm{C}$, pH 6.5-7.6. Optimum growth at salt concentrations typical of marine bacteria. Habitat: anoxic marine sediments and stagnant waters con- taining hydrogen sulfide and exposed to light, marine sponges and other marine invertebrates. The $\mathrm{G}+\mathrm{C}$ content of the DNA is $68.9-70.4 \mathrm{~mol} \%$ (Bd). Type species is Marichromatium gracile. An additional species is Marichromatium purpuratum.

\section{Description of Marichromatium gracile comb. nov.}

Marichromatium gracile (Chromatium gracile Strzeszewski 1913, 321 ${ }^{\mathrm{AL}}$ ) (gra'ci.le. L. neut. adj. gracile thin, slender). The description is the same as that for Chromatium gracile (Strzeszewski, 1913; Pfennig \& Trüper, 1989).

\section{Description of Marichromatium purpuratum comb.} nov.

Marichromatium purpuratum (Chromatium purpuratum Imhoff and Trüper 1980b, 601 ${ }^{\mathrm{VP}}$ ) (pur.pur.a'tum. L. neut. adj. purpuratum dressed in purple). The description is the same as that for Chromatium purpuratum (Imhoff \& Trüper, 1980a).

\section{Description of Thermochromatium gen. nov.}

Thermochromatium (Ther.mo.chro.ma'ti.um. Gr. adj. thermos hot; Chromatium a genus name; M.L. neut. n. Thermochromatium the hot Chromatium).

Cells are straight to slightly curved rods. Multiply by binary fission, motile most likely by polar flagella. Gram-negative. Contain internal photosynthetic membrane systems of vesicular type in which the photosynthetic pigments bacteriochlorophyll $a$ and carotenoids are located. Obligately phototrophic, photolithoautotrophic growth with sulfide or elemental sulfur as electron donor under anoxic conditions in the light. Elemental sulfur is formed as an intermediate oxidation product and stored inside the cells. Sulfate is the ultimate oxidation product. In the presence of sulfide and bicarbonate, organic substrates can be photoassimilated. Thermophilic bacteria with optimal growth temperatures at $48-50{ }^{\circ} \mathrm{C}, \mathrm{pH}$ optimum is $7 \cdot 0$. Freshwater bacteria without a requirement for significant levels of salt. Habitat: sulfide-containing hot springs of neutral to alkaline $\mathrm{pH}$. The $\mathrm{G}+\mathrm{C}$ content of the DNA is $60-63 \mathrm{~mol} \%(\mathrm{Bd})$. Type species is Thermochromatium tepidum.

\section{Description of Thermochromatium tepidum comb. nov.}

Thermochromatium tepidum (Chromatium tepidum Madigan 1986) (te'pi.dum. L. neut. adj. tepidum lukewarm). The description is the same as that for Chromatium tepidum (Madigan, 1986).

\section{Description of Allochromatium gen. nov.}

Allochromatium (Al.lo.chro.ma'ti.um. Gr. adj. allos the other; Chromatium a genus name; M.L. neut. n. Allochromatium the other Chromatium). 
Cells are straight to slightly curved rods. Multiply by binary fission, motile by polar flagella. Cells occur singly or in pairs. Gram-negative. Contain internal photosynthetic membrane systems of vesicular type in which the photosynthetic pigments bacteriochlorophyll $a$ and carotenoids are located. Photolithoautotrophic growth with sulfide or elemental sulfur as electron donor under anoxic conditions in the light. Elemental sulfur is formed as an intermediate oxidation product and stored in the form of highly refractile globules inside the cells. Sulfate is the ultimate oxidation product. Molecular hydrogen may be used as electron donor. In the presence of sulfide and bicarbonate organic substrates can be photoassimilated, potentially mixotrophic. Mesophilic bacteria with optimal growth temperatures of $25-35^{\circ} \mathrm{C}$, $\mathrm{pH}$ range 6:5-7.6. No distinct requirement for salt, except for strains that originate from the marine and brackish water environment and may tolerate or require low concentrations of salt. Habitat: ditches, ponds and lakes with stagnant freshwater containing hydrogen sulfide and exposed to light; also sewage lagoons, estuaries and salt marshes. The $\mathrm{G}+\mathrm{C}$ content of the DNA is $55 \cdot 1-66 \cdot 3 \mathrm{~mol} \%(\mathrm{Bd})$. Type species is Allochromatium vinosum. Other species are Allochromatium minutissimum and Allochromatium warmingii.

\section{Description of Allochromatium vinosum comb. nov.}

Allochromatium vinosum (Monas vinosa Ehrenberg 1838, 11; Chromatium vinosum Winogradsky 1888, $99^{\mathrm{AL}}$ ) (vi.no'sum. L. neut. adj. vinosum full of wine). The description is the same as that for Chromatium vinosum (Winogradsky, 1888; Pfennig \& Trüper, 1989).

\section{Description of Allochromatium minutissimum comb.} nov.

\begin{tabular}{|c|c|}
\hline & minutissimum \\
\hline
\end{tabular}
(mi.nu.tis'si.mum. L. neut. sup. adj. minutissimum very small, smallest). The description is the same as that for Chromatium minutissimum (Winogradsky, 1888; Pfennig \& Trüper, 1989).

\section{Description of Allochromatium warmingii comb. nov.}

Allochromatium warmingii (Monas warmingii Cohn 1875, 167; Chromatium warmingii Migula 1900, $1048^{\mathrm{AL}}$ ) (war.min'gi.i. M.L. gen. n. warmingii of Warming; named after E. Warming, a Danish botanist). The description is the same as that for Chromatium warmingii (Migula, 1900; Pfennig \& Trüper, 1989).

\section{Description of Isochromatium gen. nov.}

Isochromatium (I.so.chro.ma'ti.um. Gr. adj. isos equal, similar; Chromatium a genus name; M.L. neut. n.
Isochromatium the similar Chromatium, the bacterium similar to Chromatium).

Cells are straight to slightly curved rods, multiply by binary fission, motile by a polar tuft of flagella. Gramnegative. Contain internal photosynthetic membrane systems of vesicular type in which the photosynthetic pigments bacteriochlorophyll $a$ and carotenoids are located. Obligately phototrophic and strictly anaerobic. Under anoxic conditions in the light capable of photolithoautotrophic growth with sulfide or elemental sulfur as electron donor. Elemental sulfur is formed as an intermediate oxidation product and stored in the form of highly refractile globules inside the cells. Sulfate is the ultimate oxidation product. In the presence of sulfide and bicarbonate organic substrates can be photoassimilated. Mesophilic bacteria with optimal growth temperatures of $25-35^{\circ} \mathrm{C}, \mathrm{pH}$ range $6 \cdot 5-7 \cdot 6$. Salt is required for growth at concentrations typical for marine bacteria. Habitat: estuarine salt flats and salt marshes. The $\mathrm{G}+\mathrm{C}$ content of the DNA is $62 \cdot 2-62.8 \mathrm{~mol} \%(\mathrm{Bd})$. Type species is Isochromatium buderi.

\section{Description of Isochromatium buderi comb. nov.}

Isochromatium buderi (Chromatium buderi Trüper and Jannasch 1968, 364 ${ }^{\mathrm{AL}}$ ) (bu'der.i. M.L. gen. n. buderi of Buder; named after J. Buder, a German plant physiologist). The description is the same as that for Chromatium buderi (Trüper \& Jannasch, 1968).

\section{ACKNOWLEDGEMENTS}

We would like to express our gratitude to Professor $\mathrm{Dr} \mathrm{H}$. G. Trüper (University of Bonn, Germany) for discussion on and proposal of new names and Professor Dr N. Pfennig (Überlingen, Germany) for providing the original cultures and introduction into the handling of these creatures.

\section{REFERENCES}

Ambler, R. P., Daniel, M., Hermoso, J., Meyer, T. E., Bartsch, R. G. \& Kamen, M. D. (1979). Cytochrome $c_{2}$ sequence variation among the recognized species of purple nonsulfur photosynthetic bacteria. Nature 278, 659-660.

Burgess, J. G., Kawaguchi, R., Yamada, A. \& Matsunaga, T. (1994). Rhodobacter marinus sp. nov.: a new marine-hydrogen producing photosynthetic bacterium which is sensitive to oxygen and sulphide. Microbiology 140, 965-970.

Caumette, P., Baulaigue, R. \& Matheron, R. (1988). Characteritation of Chromatium salexigens sp. nov., a halophilic Chromatiaceae isolated from Mediterranean Salinas. Syst Appl Microbiol 10, 284-292.

Caumette, P., Baulaigue, R. \& Matheron, R. (1991). Thiocapsa halophila sp. nov., a new halophilic phototrophic purple sulfur bacterium. Arch Microbiol 155, 170-176.

Caumette, P., Imhoff, J. F., Süling, J. \& Matheron, R. (1997). Chromatium glycolicum sp. nov., a moderately halophilic purple sulfur bacterium that uses glycolate as substrate. Arch Microbiol 167, 11-18. 
DeWeerd, K. A., Mandelco, L., Tanner, R. S., Woese, C. R. \& Suflita, J. M. (1990). Desulfomonile tiedjei gen. nov. and sp. nov., a novel anaerobic, dehalogenating, sulfate-reducing bacterium. Arch Microbiol 154, 23-30.

Dickerson, R. E. (1980). Evolution and gene transfer in purple photosynthetic bacteria. Nature 283, 210-212.

Dilling, W., Liesack, W. \& Pfennig, N. (1995). Rhabdochromatium marinum gen. nom. rev., sp. nov., a purple sulfur bacterium from salt marsh microbial mat. Arch Microbiol 164, 125-131.

Eimhjellen, K. E. (1970). Thiocapsa pfennigii sp. nov. A new species of the phototrophic sulfur bacteria. Arch Mikrobiol 73, 193-194.

Eimhjellen, K. E., Steensland, H. \& Traetteberg, J. (1967). A Thiococcus sp. nov. gen., its pigments and internal membrane system. Arch Mikrobiol 59, 82-92.

Felsenstein, J. (1989). PHYLIP, phylogenetic inference package (version 3.2). Cladistics 5, 164-166.

Fowler, V. J., Pfennig, N., Schubert, W. \& Stackebrandt, E. (1984). Towards a phylogeny of phototrophic purple sulfur bacteria $16 \mathrm{~S}$ rRNA oligonucleotide cataloguing of 11 species of Chromatiaceae. Arch Microbiol 139, 382-387.

Gibson, J., Stackebrandt, E., Zablen, L. B., Gupta, R. \& Woese, C. R. (1979). A phylogenetic analysis of the purple photosynthetic bacteria. Curr Microbiol 3, 59-64.

Gorlenko, V. M. (1974). The oxidation of thiosulfate by Amoebobacter roseus in the dark under microaerophilic conditions. Mikrobiologiya 43, 729-731 (in Russian).

Guyoneaud, R., Matheron, R., Liesack, W., Imhoff, J. F. \& Caumette, P. (1997). Thiorhodococcus minus gen. nov., sp. nov., a new purple sulfur bacterium isolated from coastal lagoon sediments. Arch Microbiol 168, 16-23.

Guyoneaud, R., Süling, J., Petri, R., Matheron, R., Caumette, P., Pfennig, N. \& Imhoff, J. F. (1998). Taxonomic rearrangements of the genera Thiocapsa and Amoebobacter on the basis of $16 \mathrm{~S}$ rDNA sequence analyses and description of Thiolamprovum gen. nov. Int $J$ Syst Bacteriol 48, 957-964.

Hiraishi, A. \& Ueda, Y. (1994). Intrageneric structure of the genus Rhodobacter: transfer of Rhodobacter sulfidophilus and related marine species to the genus Rhodovulvum gen. nov. Int $J$ Syst Bacteriol 44, 15-23.

Imhoff, J. F. (1984a). Reassignment of the genus Ectothiorhodospira Pelsh 1936 to a new family, Ectothiorhodospiraceae fam. nov., and emended description of the Chromatiaceae Bavendamm 1924. Int J Syst Bacteriol 34, 338-339.

Imhoff, J. F. (1984b). Quinones of phototrophic purple bacteria. FEMS Microbiol Lett 256, 85-89.

Imhoff, J. F. (1991). Polar lipids and fatty acids in the genus Rhodobacter. Syst Appl Microbiol 14, 228-234.

Imhoff, J. F. \& Bias-Imhoff, U. (1995). Lipids, quinones and fatty acids of anoxygenic phototrophic bacteria. In Anoxygenic Photosynthetic Bacteria, pp. 179-205. Edited by R. E. Blankenship, M. T. Madigan \& C. E. Bauer. Dordrecht, The Netherlands: Kluwer.

Imhoff, J. F. \& Süling, J. (1996). The phylogenetic relationship among Ectothiorhodospiraceae. A re-evaluation of their taxonomy on the basis of rDNA analyses. Arch Microbiol 165, $106-113$

Imhoff, J. F. \& Trüper, H. G. (1980a). Chromatium purpuratum $\mathrm{sp}$ nov., a new species of the Chromatiaceae. Zentbl Bakteriol I Abt Orig C1, 61-69.
Imhoff, J. F. \& Trüper, H. G. (1980b). In Validation of the publication of new names and new combinations previously effectively published outside the IJSB, List no. 4. Int J Syst Bacteriol 30, 601.

Imhoff, J. F. \& Trüper, H. G. (1982). Taxonomic classification of photosynthetic bacteria (anoxyphotobacteria, phototrophic bacteria). In Handbook of Biosolar Resources, vol. 1, part 1, Basic Principles, pp. 513-522. Edited by A. Mitsui \& C. C. Black. Boca Raton, FL: CRC Press.

Imhoff, J. F., Petri, R. \& Süling, J. (1998). Reclassification of species of the spiral-shaped phototrophic purple non-sulfur bacteria of the $\alpha$-Proteobacteria: description of the new genera Phaeospirillum gen. nov., Rhodovibrio gen. nov., Rhodothalassium gen. nov. and Roseospira gen. nov. as well as transfer of Rhodospirillum fulvum to Phaeospirillum fulvum comb. nov., of Rhodospirillum molischianum to Phaeospirillum molischianum comb. nov., of Rhodospirillum salinarum to Rhodovibrio salinarum comb. nov., of Rhodospirillum sodomense to Rhodovibrio sodomensis comb. nov., of Rhodospirillum salexigens to Rhodothalassium salexigens comb. nov., and of Rhodospirillum mediosalinum to Roseospira mediosalina comb. nov. Int $J$ Syst Bacteriol 48, 793-798.

Jukes, T. H. \& Cantor, C. R. (1969). Evolution of protein molecules. In Mammalian Protein Metabolism, vol. 3, pp. 21-132. Edited by H. N. Munro. New York: Academic Press.

Kämpf, C. \& Pfennig, N. (1980). Capacity of Chromatiaceae for chemotrophic growth. Specific respiration rates of Thiocystis violacea and Chromatium vinosum. Arch Microbiol 127, $125-135$

Kämpf, C. \& Pfennig, N. (1986). Isolation and characterization of some chemoautotrophic Chromatiaceae. J Basic Microbiol 26, $507-515$

Kondratieva, E. N., Zhukov, V. G., Ivanovsky, R. N., Petushkova, Yu. P. \& Monosov, E. Z. (1976). The capacity of phototrophic sulfur bacterium Thiocaposa roseopersicina for chemosynthesis. Arch Microbiol 108, 287-292.

Lapage, S. P., Sneath, P. H. A., Lessel, E. F., Skerman, V. B. D., Seeliger, H. P. R. \& Clark, W. A. (editors) (1992). International Code of Nomenclature of Bacteria (1990 Revision). Bacteriological Code. Washington, DC: American Society for Microbiology.

Madigan, M. T. (1986). Chromatium tepidum sp. nov., a thermophilic photosynthetic bacterium of the family Chromatiaceae. Int J Syst Bacteriol 36, 222-227.

Migula, W. (1900). System der Bakterien. Jena: Gustav Fischer. Mullis, K. B. \& Faloona, F. (1987). Specific synthesis of DNA in vitro via a polymerase-catalysed chain reaction. Methods Enzymol 155, 335-350.

Overmann, J. \& Tuschak, C. (1997). Phylogeny and molecular fingerprinting of green sulfur bacteria. Arch Microbiol 167 , 302-309.

Perty, M. (1852). Zur Kenntnis kleinster Lebensformen, pp. 1-228. Bern: Jent und Reinert.

Pfennig, N. \& Trüper, H. G. (1974). The phototrophic bacteria. In Bergey's Manual of Determinative Bacteriology, 8 th edn, pp. 24-75. Edited by R. E. Buchanan \& N. E. Gibbons. Baltimore: Williams \& Wilkins.

Pfennig, N. \& Trüper, H. G. (1989). Family Chromatiaceae. In Bergey's Manual of Systematic Bacteriology, vol. 3, pp. 1637-1653. Edited by J. T. Staley, M. P. Bryant, N. Pfennig \& J. G. Holt. Baltimore: Williams \& Wilkins. 
Pfennig, N. \& Trüper, H. G. (1992). The family Chromatiaceae. In The Prokaryotes, pp. 3200-3221. Edited by A. Balows, H. G. Trüper, M. Dworkin, W. Harder \& K. H. Schleifer. New York: Springer.

Sanger, F., Nicklen, S. \& Coulson, A. R. (1977). DNA sequencing with chain-terminating inhibitors. Proc Natl Acad Sci USA 74, 5463-5467.

Stackebrandt, E., Fowler, V. J., Schubert, W. \& Imhoff, J. F. (1984). Towards a phylogeny of phototrophic purple sulfur bacteria the genus Ectothiorhodospira. Arch Microbiol 137, 366-370.

Strzeszewski, B. (1913). Beiträge zur Kenntnis der Schwefelflora in der Umgebung von Krakau. Bull Acad Sci Cracovie Ser B 1913, 309-334.

Thiemann, B. \& Imhoff, J. F. (1996). Differentiation of Ectothiorhodospiraceae based on their fatty acid composition. Syst Appl Microbiol 19, 223-230.

Thompson, J. D., Higgins, D. G. \& Gibson, T. J. (1994). CLUSTAL $\mathrm{W}$ : improving the sensitivity of progressive multiple sequence alignment through sequence weighting position-specific gap penalties and weight matrix choice. Nucleic Acids Res 22, 4673-4680.

Trüper, H. G. (1987). Phototrophic bacteria (an incoherent group of prokaryotes). A taxonomic versus phylogenetic survey. Microbiologia SEM 3, 71-89.

Trüper, H. G. \& Jannasch, H. W. (1968). Chromatium buderi nov. spec., eine neue Art der "großen" Thiorhodaceae. Arch Mikrobiol 61, 363-372.

Wahlund, T. M., Woese, C. R., Castenholz, R. W. \& Madigan, M. T. (1991). A thermophilic green sulfur bacterium from New Zealand hot springs, Chlorobium tepidum sp. nov. Arch Microbiol 156, 81-90.

Winogradsky, S. (1888). Zur Morphologie und Physiologie der Schwefelbakterien. In Beiträge zur Morphologie und Physiologie der Bakterien, Heft 1. Leipzig: Felix.

Woese, C. R. (1987). Bacterial evolution. Microbiol Rev 51 , $221-271$ 
